\title{
Alterations in the Phase Portrait and Electrophoretic Mobility of Erythrocytes in Various Diseases
}

\author{
DOI: $10.17691 / \mathrm{stm} 2019.11 .2 .09$
}

Received June 14, 2018

\begin{abstract}
A.V. Deryugina, DSc, Associate Professor, Head of the Department of Physiology and Anatomy, Institute of Biology and Biomedicine ${ }^{1}$;

M.N. Ivashchenko, PhD, Associate Professor, Department of Biochemistry named after G. Ya. Gorodisskaya2; P.S. Ignatiev, PhD, Head of Medical Device and Microscopy Department3;

M.S. Lodyanoy, PhD, Associate Professor, Department of Animal Physiology and Biochemestry4:

A.G. Samodelkin, DSc, Professor, Head of the Department of Animal Physiology and Biochemistry 4

${ }^{1}$ National Research Lobachevsky State University of Nizhny Novgorod, 23 Prospekt Gagarina, Nizhny Novgorod, 603950, Russia;

2Privolzhsky Research Medical University, 10/1 Minin and Pozharsky Square, Nizhny Novgorod, 603005, Russia;

${ }^{3}$ Production Association "Ural Optical and Mechanical Plant named after Mr. E.S. Yalamov", 33B Vostochnaya St., Ekaterinburg, 620100, Russia;

${ }^{4}$ Nizhny Novgorod State Agricultural Academy, 97 Prospekt Gagarina, Nizhny Novgorod, 603107, Russia
\end{abstract}

The aim of the investigation was to study a phase portrait, electrophoretic mobility of erythrocytes (EPME), and clinical and laboratory blood indices in patients with various types of diseases.

Materials and Methods. A phase portrait, EPME, and clinical and laboratory blood indices have been studied in patients with cardiovascular, bronchopulmonary, gynecological, and gastroenterological diseases. The phase portrait was investigated using laser interferometry technique, EPME was determined by microelectrophoresis. The clinical and laboratory indices included counting the number of erythrocytes and leukocytes, measurements of hemoglobin content and ESR by means of standard clinical methods. The phase portrait and EPME were studied under the action of adrenaline and cortisol in experiments in vitro.

Results. Using laser interferometry, phase images of erythrocytes in cardiovascular, gastroenterological, bronchopulmonary, and gynecological diseases have been obtained. The analysis of the gallery of erythrocyte phase images has shown that alterations were unidirectional in all types of pathologies and were characterized by the increase of echinocyte number. The morphological modification of erythrocytes correlated with EPME changes and clinical and laboratory blood indices and reflected the degree of stress and triggering of adaptive processes in the course of the conducted therapy. Influence of stress-realizing systems has been confirmed by the in vitro experiments under the action of adrenaline and cortisol.

Conclusion. Indices of EPME and erythrocyte phase portrait obtained with the help of the current techniques of cellular microelectrophoresis and laser interferometry provide the opportunity to obtain new information on the internal structure of cytoobjects without special preparations of specimens and contrast or fluorescent probes.

These indices may be applied for quantitative characteristic of the stress reaction degree and the development of adaptive processes which is of great importance for the transition to personified medicine.

Key words: laser interferometry; phase portrait of erythrocytes; electrophoretic mobility of erythrocytes.

\section{Introduction}

One of the current directions of clinical medicine is a transition to the translation medicine which implies the introduction of the results of basic researches in biomedicine into practice in order to improve the diagnosis and treatment [1]. Development and implementation of innovation technologies to optimize the diagnosis, treatment, prevention, and prediction of disease outcomes are of great scientific and practical interest.

Laser interferometry may be referred to such promising technologies. It enables the images of living functioning cells to be obtained in real time with nanometer resolution. A researcher obtains a phase cell image by registering the interference signal passing through a cytoobject. In case of transparent objects, such as a native cell, a phase image can carry information not only about its spatial characteristics but also about the distribution of optical density inside the cytoobject. A significant merit of laser interferometry is a quantitative character of the received data. In contrast to the traditional methods of optical and electron microscopy where the image represents a distribution of radiation brightness (intensity) in the plane of the photoreceiver, a phase portrait is characterized by the distribution of the standardized statistically significant

Corresponding author: Marina N. Ivashchenko, e-mail: kafedra2577@mail.ru 
value, i.e. a phase thickness of the object not dependent on the external factors and device settings [2, 3].

The aim of the investigation was to study a phase portrait, electrophoretic mobility of erythrocytes, and clinical and laboratory blood indices in patients with various types of diseases.

\section{Materials and Methods}

Blood samples of patients with cardiovascular, bronchopulmonary, gynecological, and gastroenterological diseases (20 patients in each group) have been analyzed. The diagnosis was established by physicians in compliance with the standard clinical criteria on the basis of history-taking and confirmed by the laboratory and clinical investigations.

The study complied with the Declaration of Helsinki (2013) and was approved by the Ethics Committee of National Research Lobachevsky State University of

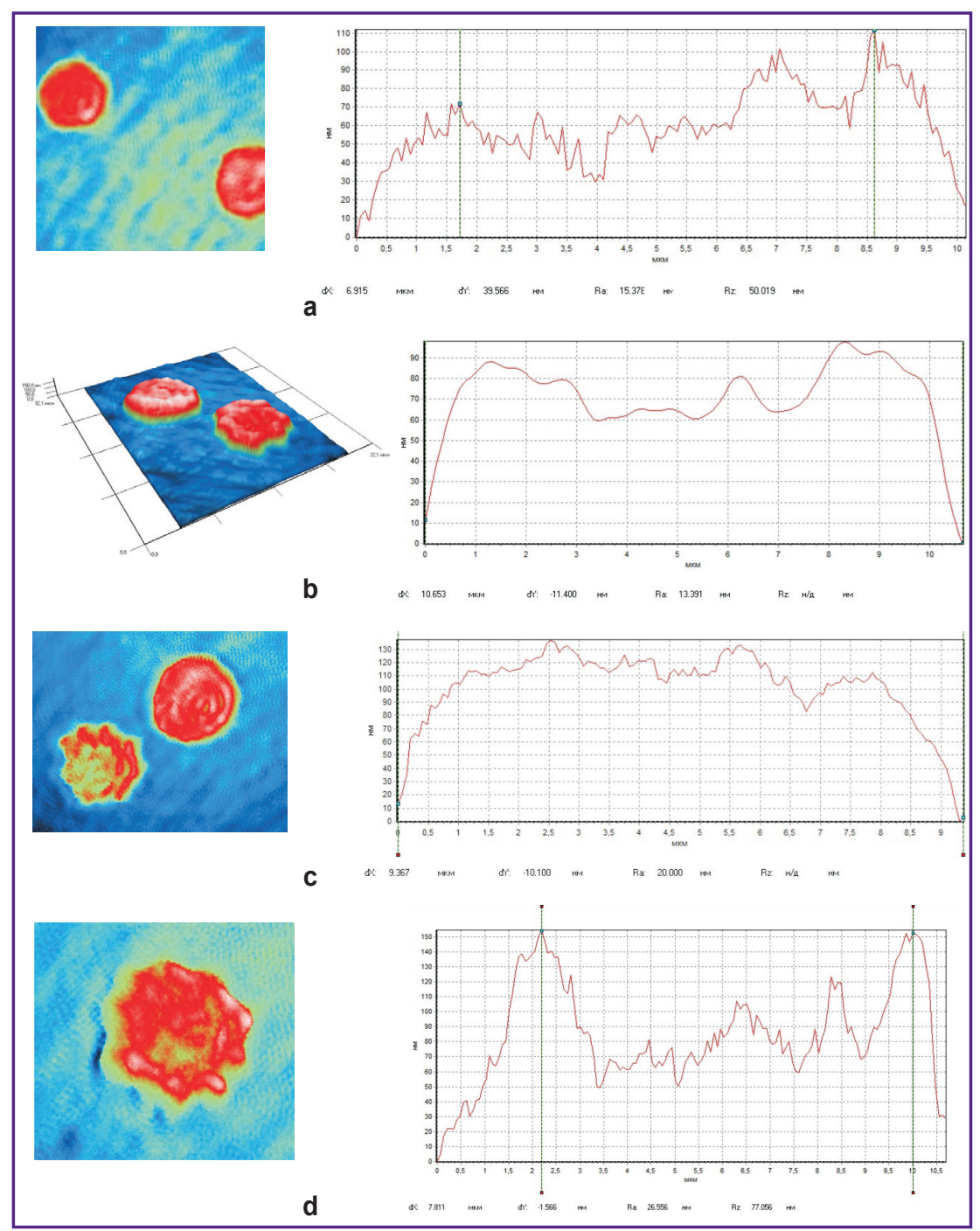

Figure 1. Phase portrait (left) and phase profile (right) of erythrocytes in:

(a) cardiovascular diseases; (b) gynecological diseases; (c) pulmonary diseases; (d) gastroenterological diseases
Nizhny Novgorod. Patients with acute condition and a written informed consent obtained in accordance with the requirements of section 9 of the Federal Law "On personal data" No.152-Ф3 of July 27, 2006 were included into the study.

Complex phasometry of erythrocytes was investigated on MIM-340 microscope (Shvabe, Russia) using laser interferometry method. A $532 \mathrm{~nm}$ laser and 20x objective with lateral resolution up to $15 \mathrm{~nm}$, vertical resolution of $0.1 \mathrm{~nm}$, and the possibility to control objects with a relief depth up to $600 \mathrm{~nm}$ were used in the work. The morphology of the native cells was registered without any preliminary fixation enabling visualization of cell modification in real time, and exploration of their morphology and dynamics of intracellular processes.

Electrophoretic mobility of erythrocytes (EPME) was measured using electrophoresis technique [4]. On the day of performing EPME, a suspension of erythrocytes was prepared and used for obtaining washed erythrocytes by centrifuging it 3 times at $1500 \mathrm{rpm}$ for $10 \mathrm{~min}$ with $0.9 \%$ solution of sodium chloride. The suspension was diluted in $10 \mathrm{mM}$ of tris- $\mathrm{HCl}$ buffer $(\mathrm{pH}$ 7.4) and EPME was measured by electrophoresis in a horizontal microchamber at $12 \mathrm{~mA}$ current.

Laboratory and clinical blood indices (hemoglobin content, total number of erythrocytes, leukocytes, and ESR) were tested by standard clinical methods [5].

A phase portrait of erythrocytes, EPME, and clinical blood tests were investigated before and after the therapeutic treatment.

Erythrocytes used for in vitro experiments were washed 3 times in $0.85 \%$ solution of sodium chloride and incubated with adrenaline $\left(1 \cdot 10^{-9} \mathrm{~g} / \mathrm{ml}\right)$ and cortisol $\left(5 \cdot 10^{-7} \mathrm{~g} / \mathrm{ml}\right)$. Each series consisted of 20 experiments.

The results of investigations were statistically processed using descriptive statistics and Student's t-test. BioStat program was used for data processing. Differences were considered statistically significant at $\mathrm{p} \leq 0.05$.

\section{Results and Discussion}

The presented phase images of erythrocytes clearly visualize in a pseudocolor the borders of the living functioning cells in cardiovascular, gastroenterological, pulmonary, and gynecological diseases (Figure 1). 


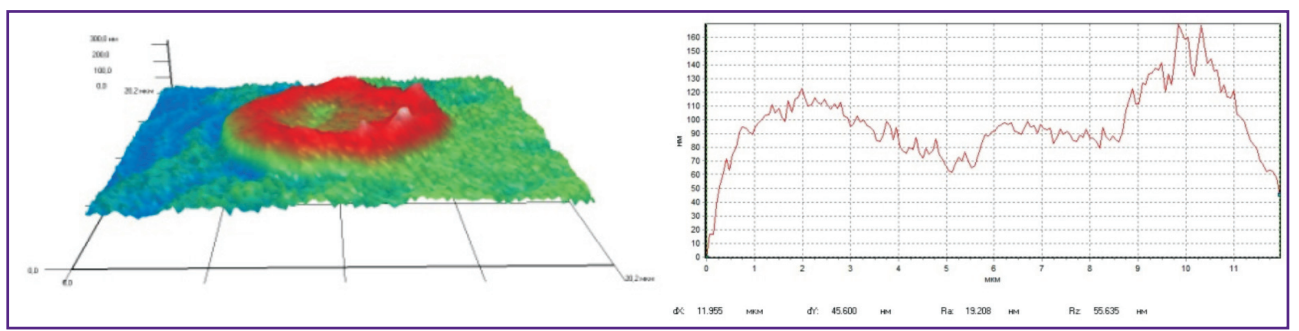

Figure 2. Phase portrait (left) and phase profile (right) of erythrocytes after the conducted therapy in all kinds of pathology

It makes it possible to assess in dynamics changes in their shape, size, and density with a high precision. Increase of echinocyte number has been found to occur in all kinds of pathology. Poikilocytosis in cardiovascular and pulmonary diseases was less evident than in gastroenterological and gynecological illnesses. Sphericity of erythrocytes increased during pulmonary and gynecological diseases.

The administered therapy resulted in the reduced portion of the morphologically altered erythrocyte shapes. Discocytes of the patients examined after the course of therapy had a rough projected surface (Figure 2). The appearance of irregularities on the cell surface is likely to be due to the initial stage of discocyte transformation into echinocytes the formation of which is restrained by the adaptive processes in the cell.

To verify the use of data obtained by erythrocyte laser interferometry as an indicator of a pathological process, these findings were compared with the results of EPME and standard clinical and laboratory investigations.

It has been previously established [6-8] that changes in EPME allow for the characterization of the stress reaction development and triggering of the adaptive body reserves. The experiments of stress simulation on animals showed [6] that decrease of EPME is observed when sympathoadrenal system is activated, whereas growth of electrophoretic mobility is associated with the activation of hypophysial-suprarenal system and enhancement of body resistance.

Investigation of clinical and laboratory blood indices and EPME of the patients has revealed their significant alterations after the conducted therapy in all examined pathologies (Table 1). Thus, growth of leukocytes and ESR prior to treatment in all diseases correlated with EPME decrease, whereas the reduction of these indices in the course of therapy was accompanied by EPME increase. The sensitivity of EPME to the changes in the body homeostasis was higher in comparison with other indices showing statistical significance of its changes in all pathologies in contrast to the clinical and laboratory indices whose significance was not always prominent.

Discussing the mechanisms of changes in the phase portrait and EPME in various pathologies before and after the treatment, it may be stated that these measurements do not depend on the etiology of the
Table 1

Changes in clinical and laboratory blood indices and electrophoretic mobility of erythrocytes (EPME) in patients with different diseases

\begin{tabular}{|c|c|c|}
\hline Tests & Before treatment & After treatment \\
\hline \multicolumn{3}{|c|}{ In cardiovascular diseases } \\
\hline Hemoglobin (g/L) & $126.00 \pm 6.28$ & $128.60 \pm 2.76$ \\
\hline Erythrocytes (x1012/L) & $4.78 \pm 0.14$ & $4.58 \pm 0.38$ \\
\hline $\operatorname{ESR}(\mathrm{mm} / \mathrm{h})$ & $14.25 \pm 1.41$ & $11.57 \pm 1.55$ \\
\hline Leukocytes (x109/L) & $9.31 \pm 0.36$ & $8.40 \pm 0.35^{*}$ \\
\hline $\operatorname{EPME}\left(\mu \mathrm{m} \cdot \mathrm{cm} \cdot \mathrm{V}^{-1} \cdot \mathrm{s}^{-1}\right)$ & $1.22 \pm 0.07$ & $1.72 \pm 0.08^{*}$ \\
\hline \multicolumn{3}{|c|}{ In pulmonary diseases } \\
\hline Hemoglobin (g/L) & $123.00 \pm 3.51$ & $133.70 \pm 3.76$ \\
\hline Erythrocytes (x1012/L) & $4.33 \pm 0.36$ & $5.03 \pm 0.53$ \\
\hline $\operatorname{ESR}(\mathrm{mm} / \mathrm{h})$ & $33.00 \pm 2.62$ & $26.33 \pm 3.36^{*}$ \\
\hline Leukocytes (x109/L) & $11.20 \pm 0.74$ & $9.67 \pm 1.20$ \\
\hline $\operatorname{EPME}\left(\mu \mathrm{m} \cdot \mathrm{cm} \cdot \mathrm{V}^{-1} \cdot \mathrm{s}^{-1}\right)$ & $1.09 \pm 0.09$ & $1.73 \pm 0.08^{*}$ \\
\hline \multicolumn{3}{|c|}{ In gynecological diseases } \\
\hline Hemoglobin (g/L) & $99.67 \pm 0.36$ & $113.20 \pm 6.49^{*}$ \\
\hline Erythrocytes (x1012/L) & $3.73 \pm 0.13$ & $4.03 \pm 0.21$ \\
\hline $\operatorname{ESR}(\mathrm{mm} / \mathrm{h})$ & $34.00 \pm 1.63$ & $29.71 \pm 2.43^{*}$ \\
\hline Leukocytes (x109/L) & $9.33 \pm 1.31$ & $8.33 \pm 0.79$ \\
\hline $\operatorname{EPME}\left(\mu \mathrm{m} \cdot \mathrm{cm} \cdot \mathrm{V}^{-1} \cdot \mathrm{s}^{-1}\right)$ & $1.15 \pm 0.06$ & $1.55 \pm 0.08^{*}$ \\
\hline \multicolumn{3}{|c|}{ In gastroenterological diseases } \\
\hline Hemoglobin $(g / L)$ & $114.70 \pm 4.77$ & $117.60 \pm 2.79$ \\
\hline Erythrocytes (x1012/L) & $3.96 \pm 0.09$ & $4.16 \pm 0.13$ \\
\hline $\mathrm{ESR}(\mathrm{mm} / \mathrm{h})$ & $13.19 \pm 1.45$ & $11.55 \pm 2.28$ \\
\hline Leukocytes (x109/L) & $10.10 \pm 0.66$ & $8.10 \pm 0.98^{*}$ \\
\hline $\operatorname{EPME}\left(\mu \mathrm{m} \cdot \mathrm{cm} \cdot \mathrm{V}^{-1} \cdot \mathrm{s}^{-1}\right)$ & $1.22 \pm 0.02$ & $1.37 \pm 0.08^{*}$ \\
\hline
\end{tabular}

* $p \leq 0.05$ relative to the level of these indices before treatment.

disease and are of the typical character. Based on the previously found dependence of EPME on the stress reaction development and triggering of the adaptive processes $[9,10]$ it may be considered that emergence of echiocytic cell transformation and EPME reduction is caused by the development of stress reaction the intensity of which is manifested by a significant EPME decrease and appearance of spheroechinocytes. But in 
Table 2

Dynamics of changes in electrophoretic mobility of erythrocytes exposed to adrenaline and cortisol in vitro $\left(\mu \mathrm{m} \cdot \mathrm{cm} \cdot \mathrm{V}^{-1} \cdot \mathrm{s}^{-1}\right)$

\begin{tabular}{lccccc}
\hline \multirow{1}{*}{ Type of exposure } & \multicolumn{5}{c}{ Time after exposure $(\mathrm{min})$} \\
& 15 & 30 & 60 & 120 & 180 \\
\hline Adrenaline & $1.24 \pm 0.05$ & $1.19 \pm 0.08^{*}$ & $1.15 \pm 0.07^{*}$ & $1.14 \pm 0.05^{*}$ & $1.16 \pm 0.04^{*}$ \\
\hline Cortisol & $1.36 \pm 0.03$ & $1.52 \pm 0.06^{*}$ & $1.96 \pm 0.06^{*}$ & $1.72 \pm 0.08^{*}$ & $1.31 \pm 0.05$ \\
\hline Physiological solution & $1.33 \pm 0.02$ & $1.36 \pm 0.06$ & $1.32 \pm 0.06$ & $1.35 \pm 0.04$ & $1.29 \pm 0.05$ \\
\hline
\end{tabular}

* Statistically significant differences between the examined and control (physiological solution) values $(p<0.05)$.

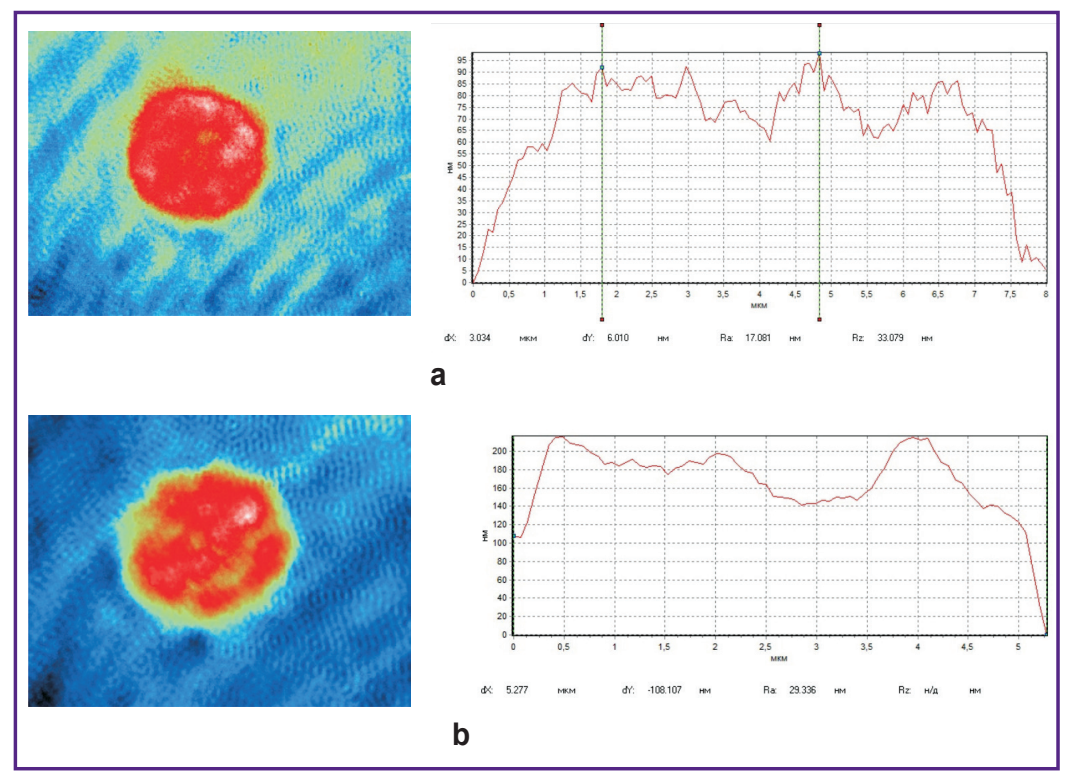

Figure 3. Phase portrait (left) and phase profile (right) of erythrocytes in vitro under the action of the examined substances:

(a) adrenaline; (b) cortisol

this case, restoration of EPME and the cell shape after therapy will signify the limitation of the stress reaction and triggering of the adaptive processes.

To confirm this statement, in vitro experiments were carried out in order to analyze the changes in EPME and morphological image of erythrocytes under the action of adrenaline and cortisol since the first phase of stress reaction is connected with the rise of adrenaline concentration in the peripheral blood and the second phase, resistance development, is connected with the increase of cortisol concentration aimed at stress elimination.

The study showed that adrenaline caused unidirectional reduction of EPME, while cortisol determined its increase (Table 2). The phase portrait of erythrocytes also changed nonuniformly: adrenaline induced the increase of cell sphericity (Figure 3 (a)), whereas the emergence of echiocytes was observed under the action of cortisol but the intensity of echinocytic transformation was insignificant (Figure 3 (b)).
Thus, the results obtained allow us to state that during the development of a pathological process, stress reaction is progressing manifesting itself in the morphological changes of erythrocytes and their electrophoretic mobility. The more intensive is the development of a pathological process, the greater manifestations of stress are observed causing growth of pathologically changed erythrocytes with spheroechinocytic transformation and EPME reduction. Interaction of adrenaline, the concentration of which correlated with the stress level, with erythrocyte receptors is accompanied by activation of phospholipase, increase of lipid peroxidation rate and partial membrane damage due to the loss of the hormone-receptor complexes from the membrane surface leading to the increase of erythrocytic membrane permeability [11]. Therapeutic measures result in stress reaction limitation which is likely to be induced by triggering of the adaptive processes in the organism under the action of cortisol involving structural changes in erythrocytes: decrease of spheroechinocyte number. But the echinocytic cells are preserved which correlates with the increased level of EPME.

\section{Conclusion}

Indices of EPME and erythrocyte phase portrait obtained with the help of the current techniques of cellular microelectrophoresis and laser interferometry provide the opportunity to obtain new information on the internal structure of cytoobjects without special preparations of specimens and contrast or fluorescent probes.

These indices may be applied for quantitative characteristic of the stress reaction degree and the development of adaptive processes which is of great importance for the transition to personified medicine. 
Study funding. The work was supported by the Russian Foundation for Basic Research within the frames of scientific project No.18-016-00195.

Conflicts of interest. The authors have no conflicts of interest to declare.

\section{References}

1. Paltsev M.A., Belushkina N.N. Translational medicine - a new stage of molecular medicine development. Molekulyarnaya meditsina 2012; 4: 16-19.

2. Naimark O.B., Nikityuk A.S., Nebogatikov V.O., Grishko V.V. Evaluation of nonlinear dynamics of the cell structure damage as a promising method for personalized cancer diagnostics. Al'manakh klinicheskoy meditsiny 2018; 46(8): 742-747.

3. Vasilenko I.A., Metelin V.B., Ignat'ev P.S., Kardashova Z.Z., Lifenko R.A. A dialogue with the cell: diagnostic real-time technology based on laser interferometry. Al'manakh klinicheskoy meditsiny 2018; 46(8): 748-757.

4. Deryugina A.V., Erofeeva E.B., Koryagin A.S. Nespetsificheskie adaptatsionnye reaktsii krovi i metody ikh opredeleniya [Non-specific adaptation reactions of the blood and methods for their determination]. Nizhny Novgorod: Izd-vo Nizhegorodskogo gosuniversiteta; 2007.

5. Klinicheskaya laboratornaya diagnostika. Natsional'noe rukovodstvo [Clinical laboratory diagnostics. National guide]. Pod red. Men'shikova V.V., Dolgova V.V. [Men'shikov V.V., Dolgov V.V. (editors)]. Moscow: GEOTAR-Media; 2012; 928 p.
6. Krylov V.N., Deryugina A.V., Pleskova S.N. Electrophoretic mobility and morphometry of the rat erythrocytes at the stress effects. Sovremennye tehnologii $v$ medicine 2010; 4: 23-26.

7. Golovetsky I.Ya., Moroz V.V., Biryukova L.S., Kozinets G.I., Popova O.V. Electrophoretic mobility of red blood cells in patients with severe forms of intoxication. Obshchaya reanimatologiya 2007 ; 3(5-6): 75-79.

8. Birjukova L.S., Purlo N.V., Kosinets G.I. Functional properties of red blood cells in hemodialysis patients with chronic renal failure (CRF) corrected by EPO. Nefrologiya $i$ dializ 2003; 5(1): 69-74.

9. Deryugina A.V., Shumilova A.V., Filippenko E.S., Galkina Y.V., Simutis I.S., Boyarinov G.A. Functional and biochemical parameters of erythrocytes during mexicor treatment in posttraumatic period after experimental blood loss and combined traumatic brain injury. Bull Exp Biol Med 2017; 164(1): 26-29, https://doi.org/10.1007/s10517-0173918-4.

10. Deryugina A.V., Ivashchenko M.N., Ignatiev P.S., Balalaeva I.V., Samodelkin A.G. Low-level laser therapy as a modifier of erythrocytes morphokinetic parameters in hyperadrenalinemia. Lasers Med Sci 2019, https://doi. org/10.1007/s10103-019-02755-y.

11. Makshanova G.P., Ust'yantseva I.M., Petukhova O.V., Agadzhanyan V.V. Change in permeability of erythrocyte membranes and in parameters of lipid metabolism in patients with multiple trauma upon early and delayed surgical treatment human physiology. Hum Physiol 2003; 29(1): 85-89. 